\title{
Upaya Meningkatkan Ekonomi Keluarga Melalui Pelatihan Dan Pendampingan Pembuatan Aneka Makanan “Jajanan Pasar” Bagi Ibu-Ibu Pkk Di Kelurahan Gebang, Masaran, Sragen
}

\author{
Septiana Novita Dewi ${ }^{1}$, Aris Tri Haryanto ${ }^{2}$, Siti Fatonah ${ }^{3}$ \\ ${ }^{1,2,3}$ Magister Manajemen STIE Adi Unggul Bhirawa Surakarta, \\ Email: Septianadewi25@yahoo.co.od, Arisharyanto26@yahoo.co.id, siti.fatonah@stie-aub.ac.id
}

\begin{abstract}
Abstrak
Di masa pandemi covid ini, banyak sekali masyarakat yang kelihangan pekerjaan, bahkan tingkat pendapatan keluarga menjadi menurun. Oleh sebab itu kegiatan Pengabdian Kepada Masyarakat ini bertujuan untuk memotivasi kembali ibu-ibu PKK khususnya di Kelurahan Gebang untuk kembali mencari kegiatan yang mampu menghasilkan pendapatan, sehingga tingkat ekonomi keluarga menjadi tertolong. Adanya wabah covid-19 ini yang sudah berjalan berbulan-bulan membuat sebagian banyak keluarga di Kelurahan Gebang merasa resah, tentang bagaimana upaya untuk mendapatkan tambahan penghasilan. Kegiatan Pengabdian Kepada Masyarakat ini, pengabdi berharap dengan adanya pelatihan teknis dan pendampingan dalam membuat aneka jajanan pasar akan membuat ketrampilan baru, sehingga ibu-ibu dapat mempraktekkannya dirumah dan bahkan bisa dijual dipasar-pasar. Aneka makanan "jajajan pasar" menjadi makanan sehari-hari, oleh sebab itu apabila ibu-ibu PKK mampu membuat aneka jajanan pasar dan mampu menarik pembeli untuk membeli, maka setidaknya mereka akan mendapatkan tambahan pendapatan. Hasil kegiatan pengabdian kepada masyarakat ini diharapkan mampu memberikan solusi bagi ibu-ibu PKK dalam meningkatkan perekonomian keluarga dan mampu menghasilkan satu karya ilmiah berupa jurnal Pengabdian Kepada Masyarakat. Dengan dilaksankaannya kegiatan PKM ini Ibu-Ibu PKK Kelurahan Gebang merasa terbantu sekali dengan ilmu yang diberikan, sehingga dapat menambahkan wawasan bagaimana proses pengemasan yang baik, pengolahan makanan yang baik serta inovasi jenis makanan yang beraneka ragam sesuai dengan kebutuhan masyarakat saat ini. Terdapat banyak jenis makanan yang diolah saat pelaksanaan PKM dan semua jenis makanan merupakan jenis makanan tradisonal yang perlu dibudidayakan bagi daerah khususnya di kelurahan Desa Gebang.
\end{abstract}

Kata Kunci : Kemandirian Ekonomi Keluarga, Jajanan Pasar, Ibu-Ibu PKK, Kelurahan Gebang

\section{PENDAHULUAN}

Perkembangan era globalisasi yang begitu cepat, mengharuskan PKK dan kader melakukan percepatan peningkatan kualitas pengetahuan dan kemampuan (Dewi et.a,l, 2020). Untuk itu, diperlukan koordinasi dan kemitraan dengan berbagai pihak, agar PKK mampu memahami dan mendayagunakan kekuatan dan peluang yang ada agar mampu meningkatkan ekonomi keluarga demi memenuhi kebutuhan sehari-hari. Ekonomi keluarga adalah suatu kajian tentang upaya manusia dalam memenuhi kebutuhankebutuhannya melalui aktivitas-aktivitas yang dilakukan oleh seseorang yang bertanggung jawab atas kebutuhan dan kebahagiaan bagi kehidupannya (sekelompok komunitas dari masyarakatnya) untuk memenuhi pangan, sandang, papan, kesehatan dan pendidikan.

Dengan adanya wabah covid-19 ini banyak masyarakat yang kelihalangan pekerjaan, adapula yang bekerja dengan waktu tertentu. Hal ini berdampak pada pendapatan ekonomi keluarga. Wabah covid-19 ini secara tidak langsung membuat masyarakat merasa resah bagaimana upaya untuk dapat bertahan demi memenuhi kebutuhan-kebutuhan sehari-hari. Kegiatan pelatihan teknis ini bertujuan agar masyarakat dapat terdorong untuk meningkatkan jiwa wirausaha dengan mengasah kembali kemampuannya untuk membuat aneka makanan "jajanan pasar" agar menjadi sampingan dalam memenuhi kebutuhan sehari-hari. Apabila kegiatan ini berhasil dan banyak masyarakat yang tertarik untuk membeli produk yang telah dibuat, maka setidaknya ibu-ibu PKK di Kelurahan Gebang akan mendapatkan pendapatan tambahan untuk memenuhi kebutuhan sehari-hari.

Salaa, (2015) menjelaskan peran ibu-ibu PKK yang mampu membuka usaha akan dapat meningkatkan pendapatan. Dengan adanya peran ibu-ibu PKK dalam mencari nafkah setidaknya akan meringankan beban keluarga dan beban suami dalam memenuhi kebutuhan mereka. Selanjutnya Salaa, (2015) juga menjelaskan bahwa walaupun ibu-ibu PKK membuka usaha rumahan, ternyata ibu-ibu PKK tidak pernah meninglkan tugas mereka sebagai ibu rumah tangga. 
Gunartin, (2019) menjelaskan bahwa dengan adanya pemberdayaan masyarakat pada prinsipnya merupakan sebuah proses kegiatan yang dapat menghasilkan suatu nilai yang lebih bermanfaat. Dalam hal ini, pemberdayaan masyarakat lebih diarahkan untuk peningkatan ekonomi keluarga. Sehingga dapat disimpulkan bahwa dengan adanya kegiatan pemberdayaan masyarakat merupakan salah satu upaya untuk memberikan daya (empowerment) kepada masyarakat agar dapat menciptakan sesuatu yang lebih bernilai.

Perekonomian keluarga akan menjadi lebih meningkat salah satunya dengan meningkatkan kemampuan atau skill yang dimiliki oleh ibu-ibu rumah tangga. Dengan adanya kemampuan dan ketrampilan yang dimiliki dalam megolah aneka makanan, akan timbul jiwa wirausaha yang akan dapat membantu meningkatkan pendapatan keluarga. Hal ini dikarenakan faktor keluarga merupakan salah satu unit terkecil dalam masyarakat yang akan mempunayi pengaruh besar terhadap kinerja pembangunan. Dari keluarga yang sejahtera ini, maka tata kehidupan berbangsa dan bernegara akan dapat mewujudkan ketenteraman, keamanan, keharmonisan, dan tingkat kemandian ekonomi.

Dalam rangka mendorong masyarakat untuk meningkatkan pendapataan, maka tim Pengabdian Kepada Masyarakat ini berupaya untuk membantu memotivasi dan mengadakan pelatihan serta pendampingan khususnya ibu-ibu PKK di Kelurahan Gebang untuk mengasah ketrampilan atau kemampuannya dalam membuat aneka makanan "jajanan pasar" yang nantinya dapat dijual baik ditetangga-tetangga maupun di pasar-pasar. Dengan adanya kegiatan Pengabdian Kepada Masyarakat ini, diharapkan dapat mengurangi tingkat pengangguran dikalangan wanita khususnya bagi ibu-ibu PKK di Keluarahan Gebang.

\section{Identifikasi Masalah}

Permasalahan utama yang dihadapi oleh masyarakat khususnya ibu-ibu PKK di Kelurahan Gebang adalah dengan adanya wabah covid-19 ini membuat pendapatan keluarga menjadi menurun. Banyak suami yang diPHK karena adanya sistem pengurangan karyawan. Selain itu diterapkannya pekerjaan dengan jawal tertentu, sehingga hal ini berdampak pada menurunnya upah yang diterima. Pada masa pandemi covid-19 ini membuat masyarakat harus berfikir bagaimana upaya untuk dapat bertahan dan memenuhi kebutuhan sehari-hari.

Adanya kegiatan pelatihan teknis dan pendampingan yang dilakukan tim Pengabdian Kepada Masyarakat ini, diharapakan ibu-ibu PKK di Kelurahan Gebang mampu mengasah kemampuannya atau ketrampilan yang dimiliki dalam membuat aneka makanan "jajanan pasar" agar dengan menghasilkan produk-produk makanan ini dapat dijual dan dapat menghasilkan tambahan pendapatan. Sehingga setidaknya ibu-ibu PKK di Kelurahan Gebang bisa mendapatkan tambahan pendapatan yang dapat digunakan untuk memenuhi kebutuhan sehari-hari.

\section{METODE PENGABDIAN}

Kegiatan PKM ini bertujuan untuk mengatasi permasalahan yang dihadapi oleh masyarakat khususnya ibu-ibu PKK di Kelurahan Gebang. Memberikan pelatihan teknis tentang cara membuat aneka makanan "jajanan pasar". Memberikan pendampingan secara berkelanjutan agar ibu-ibu PKK dapat menerapkan pelatihan yang sudah diajarkan untuk dapat menjual produk-produk yang telah dibuat.

Metode penyelesaian untuk mengatasi permasalah di atas yaitu dengan memberikan contoh gambaran manajemen alur dalam pelatihan teknis dan pendampingan dalam pembuatan aneka makanan "jajanan pasar". Khalayak sasaran dalam kegiatan Pengabdian Kepada Masyarakat ini adalah ibu-ibu PKK di Kelurahan Gebang, Kecamatan Masaran, Kabupaten Sragen. 


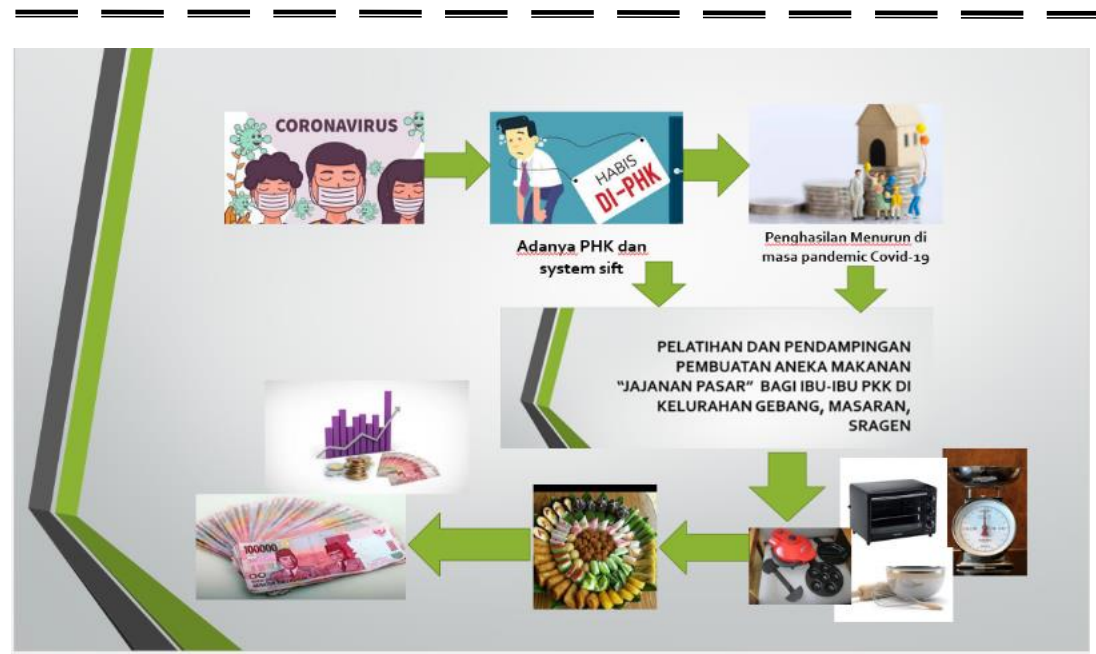

Gambar 1. Alur Pelatihan Teknis dan Pendampingan

Bentuk kegiatan pengabdian masyarakat ini adalah sebagi berikut:

1. Pelatihan teknis. Pada tahap ini adanya pelatihan secara teknis atau praktek membuat aneka makanan "jajajan pasar" di damping dengan seorang ahli dalam membuat aneka jajanan pasar.

2. Pendampingan manajemen dalam mengemas dan memasarkan produk olahan yang dihasilkan.

3. Mengevaluasi kegiatan program.

\section{HASIL DAN PEMBAHASAN}

a. Aneka Jajanan Pasar

Aneka jenis jajajan pasar yang dibuat oleh Ibu-Ibu PKK di Kelurahan Gebang sangat beragam salah satunya adalah dengan praktek membuat, putu ayu, utri, apem, karanggesing, martabak mini, sosis, wajik serta kue sagu mutiara dan masih banyak lainnya. Proses pembuatan jajananan makanan ini tergolong mudah dan menggunakan peralatan yang sederhana, hanya menggunakan alat cetakan bulat untuk membuat apem, martabak mini serta cetakan putu ayu yang berbentuk bunga-bunga. Kemudian menggunakan mixer untuk mengaduk serta menggunakan alat kukus seperti dandang yang digunakan untuk mengukus makanan. Hasil makanan yang berhasil diolah dalam praktek kegiatan PKM ini salah satunya adalah sebagai berikut:

1) Putu Ayu

Makanan ini rasanya gurih dan manis dan ditampilkan dengan menggunakan cetakan berbentuk bunga dengan menggunakan bahan telur, garam, gula pasir, tepung terigu, cake emulsifier, vanili bubuk, santan cair, perisa pandan, dan pewarna makanan berwarna hijau. Proses pembuatannya adalah semua adonan dimasukkan dalam cetakan kemudian dikukus hingga matang. Berikut adalah gambar makanan putu ayu yang dihasilkan:
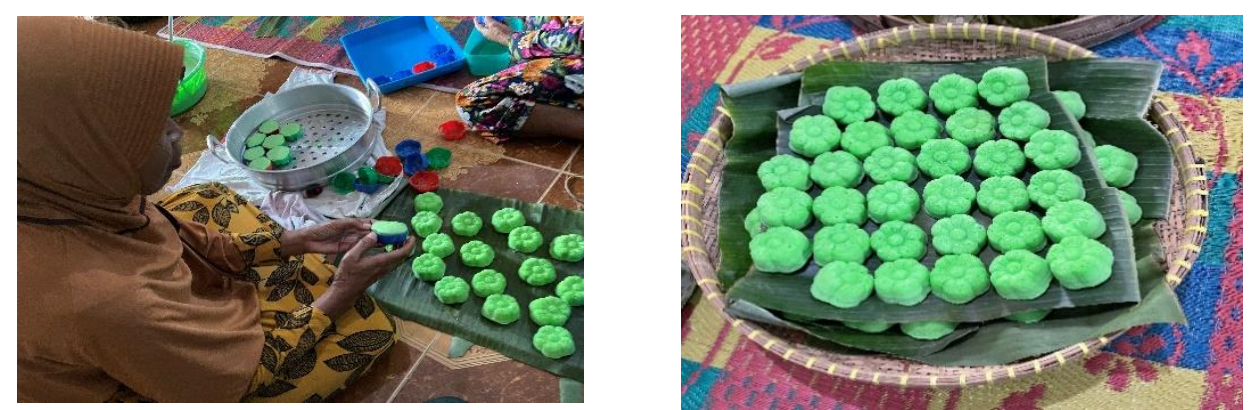

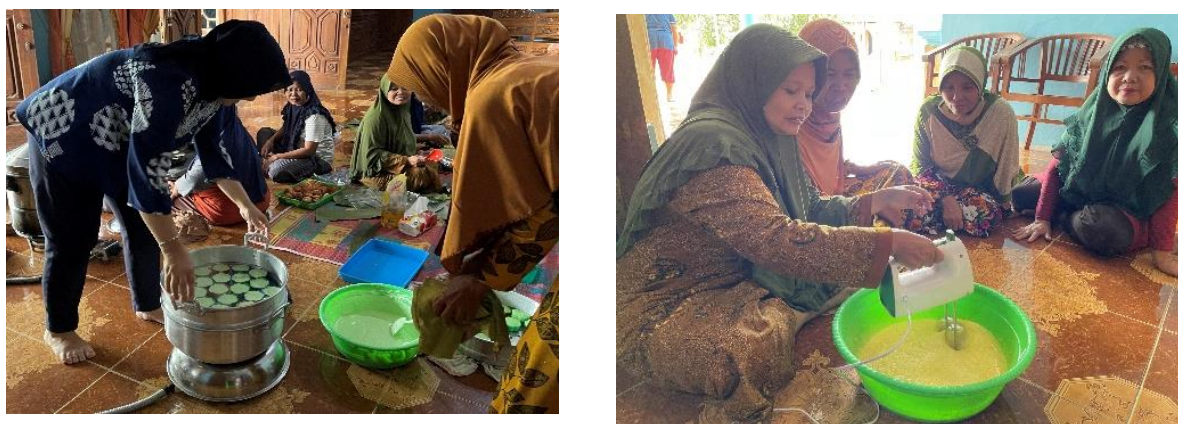

Gambar 1. Jajanan Pasar "Putu Ayu"

2) Utri

Utri adalah jenis makanan tradisional yang terbuat dari bahan baku singkong, yang kemudian dihaluskan dengan menggunakan alat "parut" dalam Bahasa jawa dan dicampur dengan gula sedikit garam, kelapa muda, gula jawa yang kemudian dicampur jadi satu dan dimasukkan ke dalam daun pisang kemudian dibentuk sesuai selera.
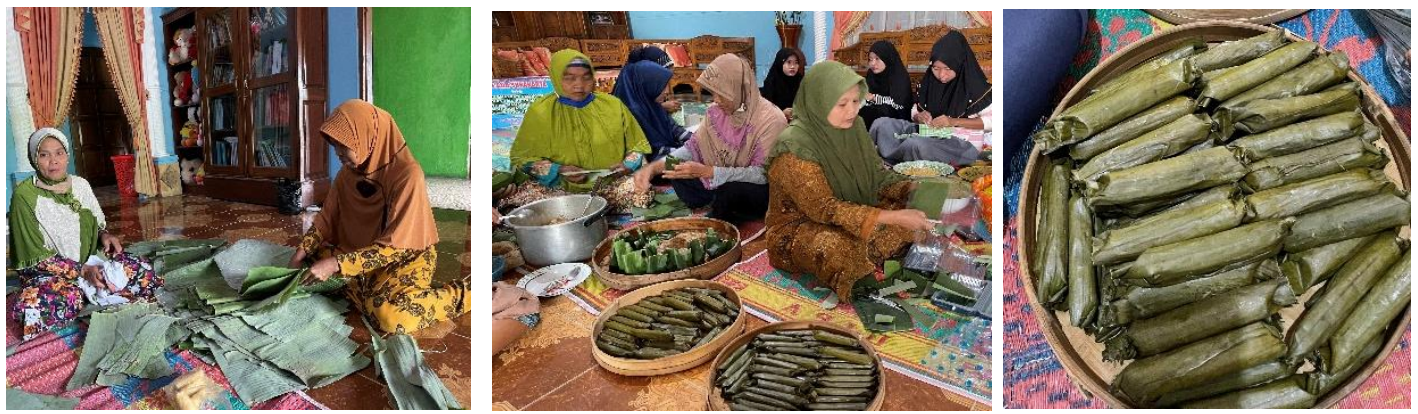

3) Karanggesing

Gambar 2. Jajanan Pasar "Utri”

Makanan tradional karanggesing merupakan sebutan makanan untuk Bahasa jawa, yang merupakan makanan yang terbuat dari pisang yang sudah dipotong-potong kecil, santan kental, gula pasir, sedikit garam, telur dikocok lepas, daun pandan, serta daun pisang yang digunakan untuk membungkus makanan. Setelah semua bahan dicampur jadi satu wadah kemudian diaduk dan di bungkus menggunakan daun pisang dan ditusuk denga lidi agar makanan bisa membentuk dengan baik. Setelah itu dapat dikukus hingga matang ketika daun sudah berwarna kecoklatan
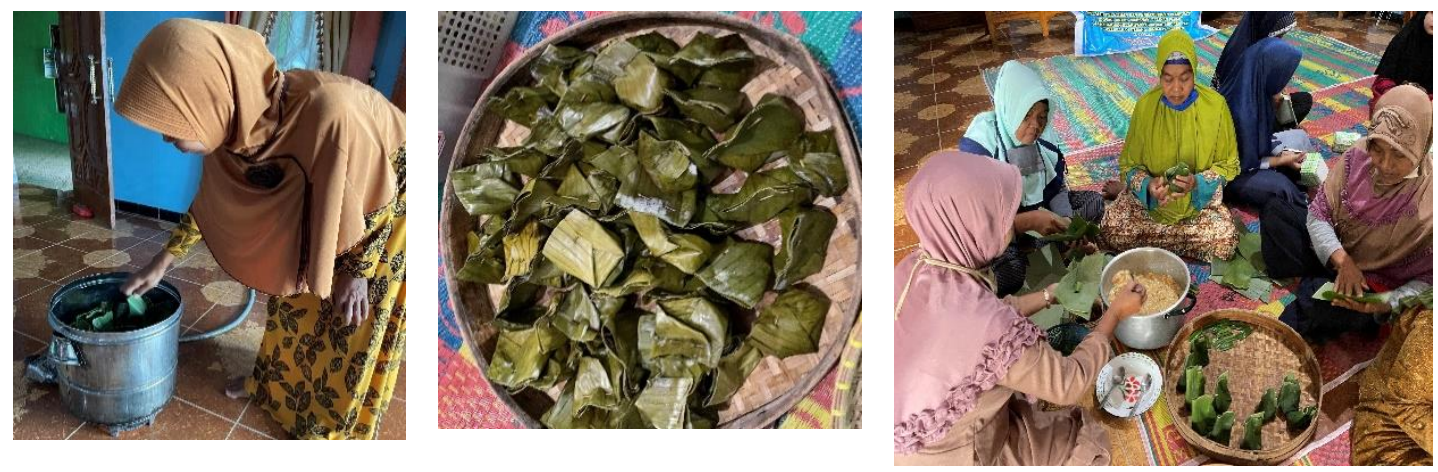

4) Martabak Mini

Gambar 3. Jajanan Pasar "Karanggesing”

Jenis makanan martabak mini adalah martabak manis yang berbentuk kecil. Bahan pokok yang dapat digunakan untuk membuat martabak mini diantaranya adalah tepung terigu, telur, baking powder, ragi instan, soda kue, susu bubuk, gula pasir, air putih, mentega yang telah dilelehkan, susu kental manis serta tambahan topping yang digunakan adalah mesis, keju. 

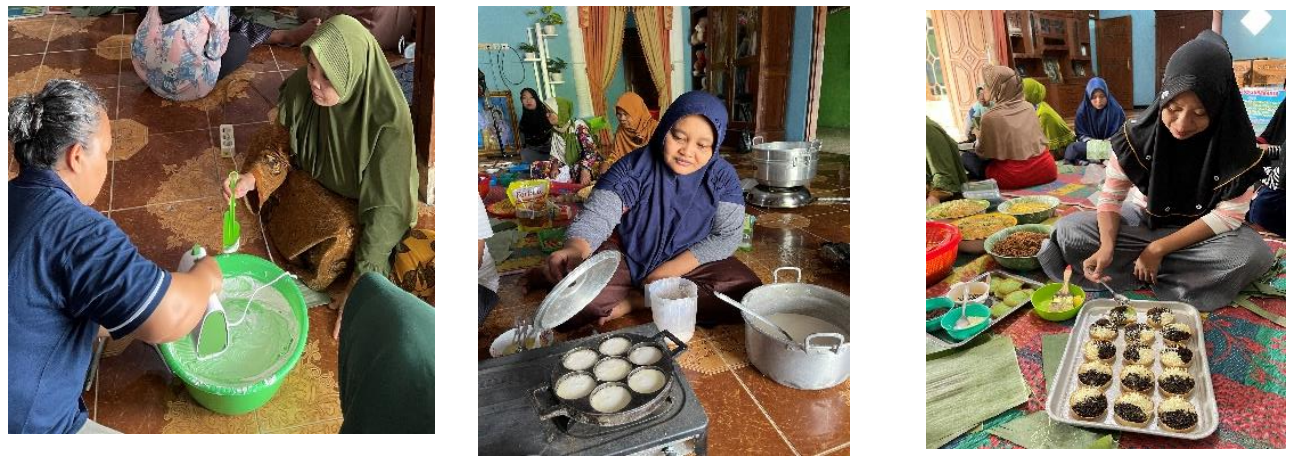

Gambar 3. Jajanan Pasar "Martabak Mini”

Kegiatam PKM ini menghasilkan banyak jenis makanan tradisional, hal ini bertujuan agar banyaknya inovasi makanan yang dapat diolah oleh Ibu-Ibu PKK sehingga dapat digunakan sebagai referensi dalam membuat aneka makanan dan dapat dijual dipasar-pasar sehingga akan menambah pendapatan bagi Ibu-Ibu PKK Kelurahan Gebang. Berbagai jenis makanan yang sudah jadi dan sudah dihias dapat disajikan sebagai berikut:
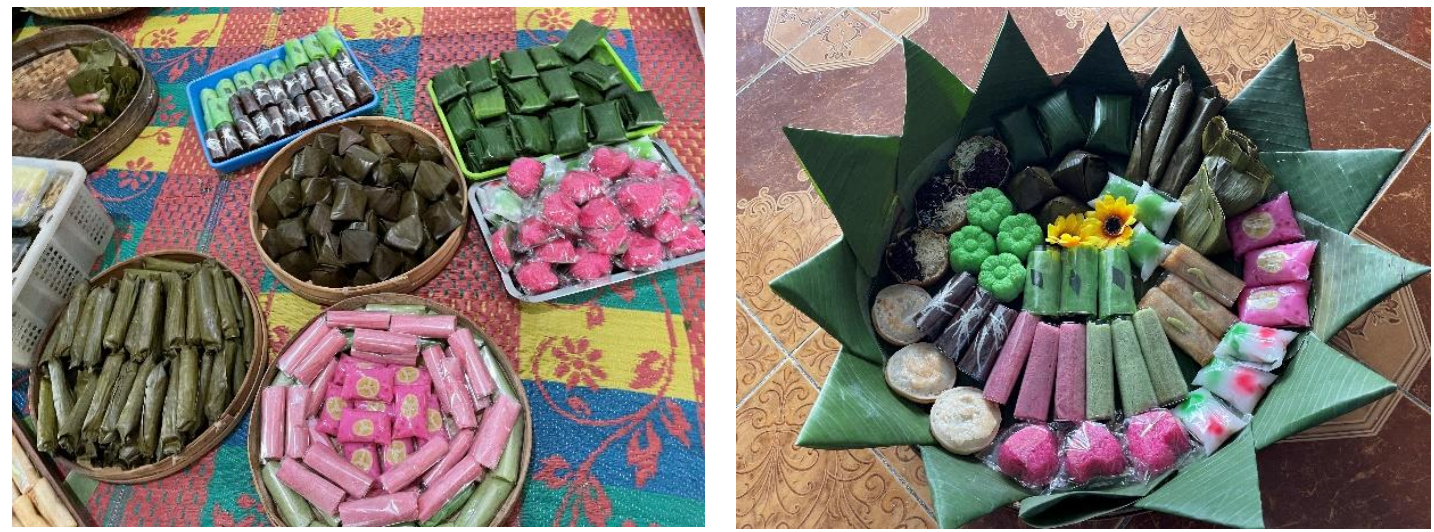

Gambar 4. Aneka Ragam Jajanan Pasar

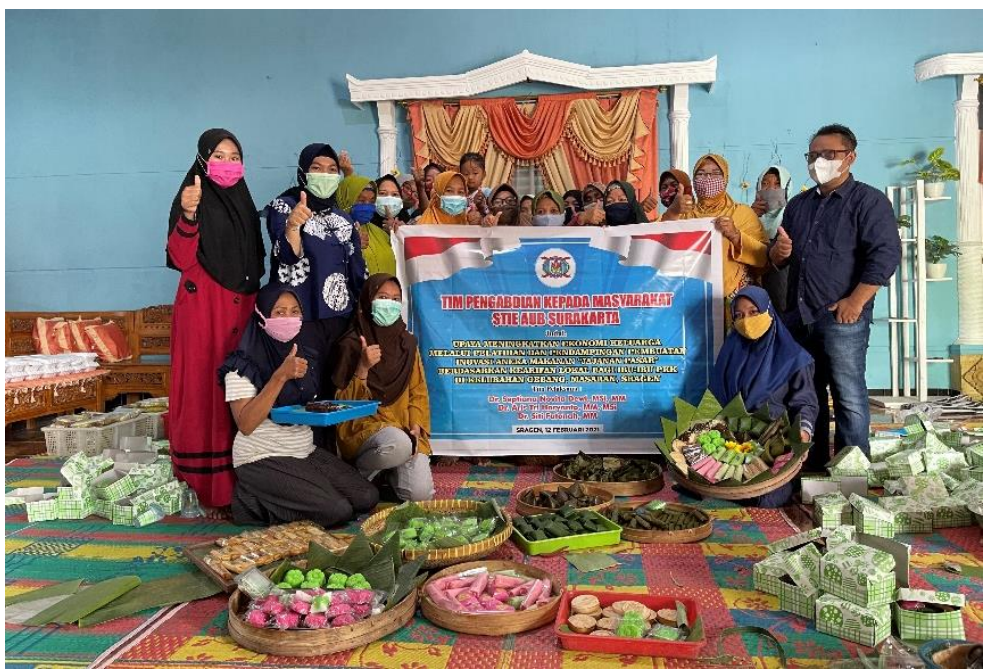

Gambar 5. Tim Pengabdian Kepada Masyarakat 


\section{SIMPULAN}

Simpulan yang dapat diberikan dalam proses kegiatan Pengabdian Kepada Masyarakat ini adalah Tim pengabdian sudah melaksanakan kegiatan dengan cara memberikan pelatihan dan sosialisasi kepada Ibu-Ibu PKK Kelurahan Gebang tentang bagaimana upaya untuk mendapatkan uang tambahan dimasa pandemi covid-19 ini. Dengan adanya usaha tersebut akan mampu meningkatkan perekonomian keluarga dan nantinya akan dapat meningkatkan kesejahteraan masyarakat khususnya bagi Ibu-Ibu PKK Kelurahan Gebang. Dengan dilaksanakan kegiatan PKM ini dapat meningkatkan kemampuannya dalam mengolah aneka makanan "jajanan pasar" seperti putu ayu, utri, karanggesing, martabak mini, apem, sosis, wajik serta kue sagu mutiara dan masih banyak lainnya. Dengan dilakukan pengabdian ini ibu-ibu PKK di Kelurahan Gebang dapat mengetahui cara membuat makanan dan mmeiliki kemampuan serta pengetahuan yang luas tentang pemahaman pengelolaan makanan yang berkualitas, memiliki daya tarik yang tinggi serta dapat memberikan makanan yang sehat bagi masyarakat.

\section{SARAN}

Saran yang dapat diberikan adalah diharapkan adanya kegiatan sosialaisasi dan pendampingan secara berkelanjutan, misalnya adanya kegiatan Pengabdian Kepada Masyarakat terkait bagaimana proses pengemasan yang menarik, serta bagaimana strategi pemasaran yang baik di era modern seperti ini dan bagaimana Ibu-Ibu PKK Kelurahan Gebang mengenal digital marketing, sehingga dapat memasarkan produknya dengan baik.

\section{DAFTAR PUSTAKA}

Dewi, S. N., Haryanto, A. T., \& Wariati, A. (2020). Pelatihan Pemasaran Produk Berbasis Digital Di Kelurahan Gebang, Masaran, Sragen. Adi Widya: Jurnal Pengabdian Masyarakat, 4(1).

Gunartin, Sunarsi \& Hidayati, 2019. Peningkatan Ekonomi Keluarga Melalui Pemberdayaan Masyarakat Dengan Membuat Sandal Hias. Jurnal Pengabdian Dharma Laksana Mengabdi Untuk Negeri. Vol. 1, No. 2, Januari 2019 ISSN : 2621-7155 E-ISSN : 2621-7147

https://analisadaily.com/berita/arsip/2017/12/5/463346/mendorong-ekonomi-keluarga-melalui-pkk/ di akses pada tanggal 30 November 2020

Salaa, 2015. Peran Ganda Ibu Rumah Tangga Dalam Meningkatkan Ekonomi Keluarga Di Desa Tarohan Kecamatan Beo Kabupaten Kepulauan Talaud . Jurnal Holistik Tahun VIII No. 15 / Januari t Juni 2015

Susanti, Rohaeni \& Jubaedah, 2014. Manfaat Hasil Penyuluhan Usaha Peningkatan Pendapatan Keluarga Sejahtera (UPPKS) Dalam Upaya Pemberdayaan Ekonomi Keluarga. Jurnal Manajemen Vol. 2 No. 1 ISSN 1979 - 6714 Desember 2014

SN Dewi, JS Riyadi, AT Haryanto, (2020) Dimensi Social Media Marketing Dalam Meningkatkan Keputusan Pembelian Produk UMKM Di Wilayah Boyolali Dengan Kemampuan Inovasi Sebagai Variabel Mediasi. ProBank : Jurnal Ekonomi Dan Perbankan ISSN : 2579-5597 (online) Vol 5, No 1 (2020)

Tuwu, 2018. Peran Pekerja Perempuan Dalam Memenuhi Ekonomi Keluarga: Dari Peran Domestik Menuju Sektor Publik. Al Izzah: Jurnal Hasil-Hasil Penelitian-ISSN: 1978-9726 (p); 2541 0717 (e) Volume 13, Nomor 1 (Mei, 2018) 